Article

\title{
Luminescent Properties of (004) Highly Oriented Cubic Zinc Blende ZnO Thin Films
}

\author{
Narcizo Muñoz-Aguirre ${ }^{1,2, *, \dagger}{ }^{\text {, Lilia Martínez-Pérez }}{ }^{2,3, \dagger}$, Severino Muñoz-Aguirre ${ }^{4}$ (D), \\ Luis Armando Flores-Herrera ${ }^{1}\left[\right.$, Erasto Vergara Hernández ${ }^{5}\left(\mathbb{D}\right.$ and Orlando Zelaya-Angel ${ }^{2, \dagger}$
}

1 Instituto Politécnico Nacional, Sección de Estudios de Posgrado e Investigación, Escuela Superior de Ingeniería Mecánica y Eléctrica Unidad Azcapotzalco. Av. Granjas No. 682, Colonia Santa Catarina, Del. Azcapotzalco, CP. 02250 Ciudad de México, Mexico; lafloresh@ipn.mx

2 Departamento de Física del Centro de Investigación y de Estudios Avanzados del IPN, C.P. 07351 Ciudad de México, Mexico; lmartin@ipn.mx (L.M.-P.); ozelaya@fis.cinvestav.mx (O.Z.-A.)

3 Unidad Profesional Interdisciplinaria en Ingeniería y Tecnologías Avanzadas del Instituto Politécnico Nacional, Av. IPN No. 2580, Col. Barrio La Laguna Ticomán, C.P. 07340 Ciudad de México, Mexico

4 Benemérita Universidad Autónoma de Puebla, Facultad de Ciencias Físico Matemáticas, Av. San Claudio y 18 sur, Col. San Manuel (CU), Puebla, Puebla, C.P. 72570, Mexico; smunoz@fcfm.buap.mx

5 Instituto Politécnico Nacional, UPIIH, San Agustín Tlaxiaca, 42162, Hidalgo, Mexico; erasto99@hotmail.com

* Correspondence: nmunoz@ipn.mx; Tel.: +52-555-729-6000 (ext. 64500)

† Departamento de Física del Centro de Investigación y de Estudios Avanzados del IPN (Affiliation 2) of sabbatical year 2017-2018.

Received: 21 May 2019; Accepted: 21 June 2019; Published: 11 October 2019

\begin{abstract}
Photoluminescence properties of cubic zinc blende $\mathrm{ZnO}$ thin films grown on glass substrates prepared by the spray pyrolysis method are discussed. X-ray diffraction spectra show the crystalline wurtzite with preferential growth in the (002) orientation and a metastable cubic zinc blende phase highly oriented in the (004) direction. Raman measurements support the $\mathrm{ZnO}$ cubic modification growth of the films. Photoluminescence (PL) spectra of zinc blende films are characterized by a new PL band centerd at $2.70 \mathrm{eV}$, the blue emission, in addition there are two principal bands that are also found in hexagonal $\mathrm{ZnO}$ films with the peak positions at $2.83 \mathrm{eV}$ and $2.35 \mathrm{eV}$. The origin of the $2.70 \mathrm{eV}$ band can be attributed to transitions from $\mathrm{Zn}$-interstitial to $\mathrm{Zn}$-vacancies. It is also important to mention that the PL intensity of the $2.35 \mathrm{eV}$ band of the zinc blende thin films is relatively higher than in the band present in hexagonal $\mathrm{ZnO}$ films, which means that zinc blende films have more oxygen vacancies, as was corroborated by means of the energy dispersion spectroscopy (EDS) measurements. PL spectra at $77^{\circ} \mathrm{K}$ were measured and the $2.70 \mathrm{eV}$ band was confirmed for the zinc blende films. Some PL bands of cubic films also appeared for the hexagonal phase, which is due, to a certain extent, to the similar ions stacking of both wurtzite and zinc blende symmetries.
\end{abstract}

Keywords: highly oriented crystals; $\mathrm{ZnO}$ thin films; spray pyrolysis technique; photoluminescence; wurtzite; zinc blende; optical properties

\section{Introduction}

Zinc oxide $(\mathrm{ZnO})$ is a highly versatile compound material because of its multiple industrial applications. As a semiconductor, $\mathrm{ZnO}$ thin films have many important applications, principally as sensors and optoelectronic materials [1-6]. Another interesting application is related to its use as a transparent conductor $[7,8]$. Therefore, researching its structural, electrical and optical properties is of wide importance. For example, Martínez Pérez et al. [7] reported the synthesis of good quality ZnO thin films by means of the spray pyrolysis technique. When chemical methods are used for depositing films, such as spray pyrolysis, it is well known that the physical properties of the resultant $\mathrm{ZnO}$ thin 
films depend on the molar concentration of the solvents and the preparation conditions of the source solution [7]. Therefore, for the same molar concentrations in the spray pyrolysis technique, if the ambient conditions of the source solution are modified then the physical properties of the deposited thin films should be different. In this research work, we show an example proving this hypothesis, and consequently a phase change from wurtzite (WZ) to zinc blende (ZB) was obtained at ambient conditions in the growth of undoped $\mathrm{ZnO}$ thin films on glass substrates. Ashrafi and Jagadish [9] remarked on the importance of obtaining a stable $\mathrm{ZB}$ phase of $\mathrm{ZnO}$ thin films for their potential applications. Also, investigations on the growth of the cubic phase in $\mathrm{ZnO}$ thin films have recently been reported. Rosales-Córdova et al. [10] reported the detection of the zinc blende phase in doped wurtzite $\mathrm{ZnO}$ thin films. Wang Xiao-Dan et al. [11] reported on cubic $\mathrm{ZnO}$ thin films deposited at a low pressure by means of the molecular beam epitaxy technique. In a previous work [12], we reported the synthesis of metastable zinc blende $\mathrm{ZnO}$ thin films. Their structural nanometric properties and the optical band gap were studied. In relation to their optical emission properties, in this work it is shown that the traditional photoluminescence (PL) bands [13-19] for hexagonal wurtzite $\mathrm{ZnO}$ thin films are maintained and new bands appear for cubic zinc blende $\mathrm{ZnO}$ thin films. The luminescent properties of hexagonal $\mathrm{ZnO}$ as material with a wide band gap has been widely studied in a very recent review [20], in which a large variety of electronic and optoelectronic devices were described. Cubic $\mathrm{ZnO}$, with a band gap of approximately the same value and with very similar physical properties as those studied in this work, can cover the same applications. $\mathrm{ZnO}$ offers the prospect of replacing the gallium nitride used in most opto-luminescent devices, with the advantage of being a cheaper material. To date, $\mathrm{ZnO}$ nanorod-based light-emitting lasers have been reported, for which enhanced stimulated emission from very small size structures has been demonstrated [21]. Hybrid nanostructures have been fabricated by means of $\mathrm{ZnO}$ and graphene, which emit white light [22]. Jin et al. [23] reported violet and UV from $\mathrm{ZnO}$ thin films deposited on sapphire by using the laser ablation technique. Additionally, optical oxygen gas sensing by means of exciton emission detection extends the optical applications of this semiconductor [24]. Doping is also used to improve some properties with a specific purpose, as is the case where $\mathrm{ZnO}: \mathrm{B}$ widens the range of luminescent emission [25], and for $\mathrm{Zn}_{1-\mathrm{x}} \mathrm{Cr}_{\mathrm{x}} \mathrm{O}$ where $\mathrm{Cr}$ increases the optical conductivity with respect to the undoped material [26].

The principal aim of this work is to show a new PL band of the cubic films at $2.70 \pm 0.05 \mathrm{eV}$ when compared with the hexagonal phase emissions, and the possible relation between the band and the structural properties of the material. The emission at $2.7 \mathrm{eV}(\lambda=460 \mathrm{~nm})$ corresponds to a light blue color, which is precisely the emission of InGaN Light-Emitting Diodes [27,28]. This fact could conduce, after some engineering process, to the preparation of cubic $\mathrm{ZnO}$-based blue emission devices.

\section{Materials and Methods}

Using the procedure detailed in [7], an ultrasonic spray pyrolysis deposition system was used to synthesize $\mathrm{ZnO}$ thin films. Source materials solutions of 0.3032 molar concentrations of zinc acetylacetonate, from Sigma Aldrich (México), dissolved in N,N-dimethylformamide (N,N-DMF), from Mallinckrodt México, were prepared. A source solution was prepared at the same conditions (stirred for $24 \mathrm{~h}$ ) as those reported in [7] and is denoted as solution A (Samples $Z_{5}, Z_{6}, Z_{7}, Z_{8}$ ). Another solution was prepared under different conditions (stirred for $48 \mathrm{~h}$ ) and is denoted as solution $B$ (Samples $Z_{1}, Z_{2}$, $Z_{3}, Z_{4}$ ). A spray from the solutions was produced by means of an ultrasonic generator operated at $0.8 \mathrm{MHz}$. High purity air at flow rates of approximately $10 \mathrm{~L} / \mathrm{min}$ was used as the carrier of the spray to the top of the substrate for 5 minutes. To achieve pyrolysis, a molten tin bath was the substrate heater. Corning glasses were used as substrates, which were carefully cleaned using a well-known cleaning procedure [16]. The depositions were carried out at substrate temperatures of $400{ }^{\circ} \mathrm{C}\left(\mathrm{Z}_{1}\right.$, $\left.Z_{5}\right), 450{ }^{\circ} \mathrm{C}\left(Z_{2}, Z_{6}\right), 500{ }^{\circ} \mathrm{C}\left(Z_{3}, Z_{7}\right)$ and $550{ }^{\circ} \mathrm{C}\left(Z_{4}, Z_{8}\right)$. To explore the structural properties and stoichiometry of the $\mathrm{ZnO}$ thin films, a field emission JEOL (Tokyo, Japan) scanning electron microscopy was used. Images of the sample surfaces and energy dispersion spectroscopy (EDS) measurements were carried out. To identify the crystalline phases, X-ray diffraction (XRD) measurements were 
made using a D-5000 Siemens (Germany) Diffractometer. For the photoluminescence measurements a Spectrofluorometer Rf5301 from Shimadzu (Japan) was used. Raman spectroscopy was carried out in a Horiba Jobin Yvon LabRAM micro-Raman system equipped with a He-Ne laser emitting at $632.8 \mathrm{~nm}$. All the characterizations were carried out at room temperature (RT).

\section{Results and Discussion}

EDS measurements show $49.78 \%$ of oxygen $(\mathrm{O})$ and $50.22 \%$ of zinc $(\mathrm{Zn})$ atomic concentrations for type A samples, and 45.37\% (O) and 54.63\% $(\mathrm{Zn})$ for type B samples, as was reported in [12]. It can be noted there was a lack of oxygen of the order of $4.63 \%$ in the crystalline network of the B samples. Figure 1 shows the $X$-ray diffraction patterns for the thin films $A$ (samples $Z_{5}, Z_{6}, Z_{7}, Z_{8}$ ) and $B$ (samples $Z_{1}, Z_{2}, Z_{3}, Z_{4}$ ). From Figure 1, the hexagonal wurtzite crystalline phase for type A films, highly oriented in the c-axe direction (002), can be observed. The B films showed high orientation in the (004) direction at $2 \theta$ equals 44.6 degrees. Such a peak is characteristic of the cubic zinc blende crystalline phase, as reported in the literature [9,17-19]. The thicknesses of the hexagonal thin films are in the range of $450 \pm 30 \mathrm{~nm}$ and the cubic thicknesses are in the $350 \pm 20 \mathrm{~nm}$ range, as estimated by profilometer measurements.

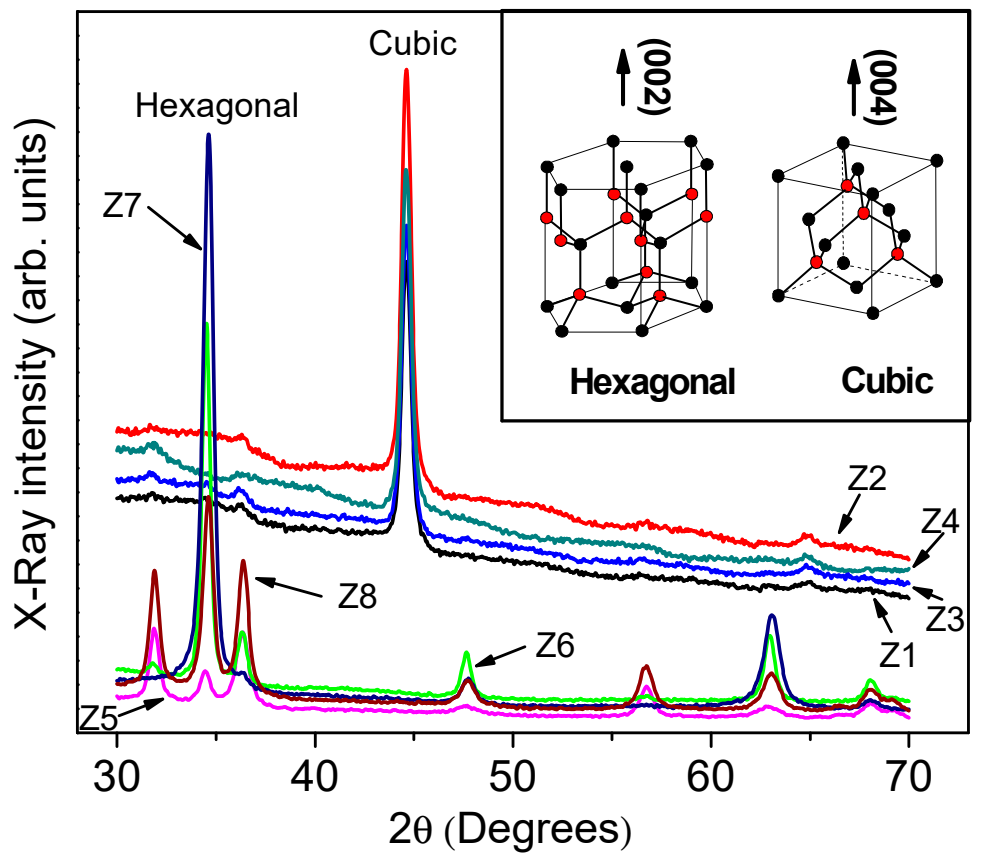

Figure 1. X-ray diffraction patterns of the films showing the cubic (zinc blende) and hexagonal phases. Substrate temperatures are $400{ }^{\circ} \mathrm{C}\left(Z_{1}, Z_{5}\right), 450{ }^{\circ} \mathrm{C}\left(Z_{2}, Z_{6}\right), 500{ }^{\circ} \mathrm{C}\left(Z_{3}, Z_{7}\right)$ and $550{ }^{\circ} \mathrm{C}\left(Z_{4}, Z_{8}\right)$. The inset illustrates the lattice of both $\mathrm{ZnO}$ phases and their preferred orientation of the films.

XRD data are used to calculate the average crystallite size (d) from the full-width at half-maximum (FWHM) of highest-intensity XRD peaks applying Debye-Scherrer's equation [29-32]:

$$
d=\frac{K \lambda}{\Delta(2 \theta) \cos \theta}
$$

where $\lambda=1.5406, \AA$ is the wavelength of the X-ray source, $\theta$ is the Bragg diffraction angle at a peak position, $\Delta(2 \theta)$ is the FWHM of the corresponding peak $\mathrm{y}$ and $K \sim 0.9$ is a correction factor. The average crystallite sizes were estimated in the range of $d=14-20 \mathrm{~nm}$ for the hexagonal wurtzite phase (using the (002) reflection) and from 15 to $17 \mathrm{~nm}$ for the zinc blende phase (using the (004) reflection). The results for each sample are presented in Table 1. From the values in this table, a decrease of the crystallite size as the deposition temperature increases can be observed. No appreciable 
shifts of the characteristic XRD peaks were observed. The sizes of the crystallite correspond to the nanostructures formed in zinc blende films, as can be observed in the SEM image in Figure 2.

Table 1. Crystallite size of the samples.

\begin{tabular}{|c|c|c|c|c|}
\hline \multicolumn{1}{|c|}{ Phase } & Sample & $\begin{array}{c}\text { Full-Width at } \\
\left.\text { Half-Maximum } \mathbf{(}^{\circ}\right)\end{array}$ & $\left.\mathbf{2 \theta} \mathbf{(}^{\circ}\right)$ & $\boldsymbol{d}(\mathbf{n m})$ \\
\hline \multirow{3}{*}{ Hexagonal } & $Z_{5}$ & 0.6160 & 34.6200 & $13.362 \pm 0.24$ \\
\cline { 2 - 5 } & $Z_{6}$ & 0.4276 & 34.5014 & $19.452 \pm 0.53$ \\
\cline { 2 - 5 } & $Z_{7}$ & 0.5491 & 34.6088 & $15.152 \pm 0.27$ \\
\cline { 2 - 5 } & $Z_{8}$ & 0.6062 & 34.6200 & $13.762 \pm 0.35$ \\
\hline \multirow{3}{*}{ Cubic } & $Z_{1}$ & 0.5163 & 44.6148 & $16.629 \pm 0.30$ \\
\hline & $Z_{2}$ & 0.5118 & 44.6186 & $16.777 \pm 0.55$ \\
\hline & $Z_{3}$ & 0.5500 & 44.6200 & $15.613 \pm 0.11$ \\
\hline & $Z_{4}$ & 0.5742 & 44.6000 & $14.953 \pm 0.18$ \\
\hline
\end{tabular}
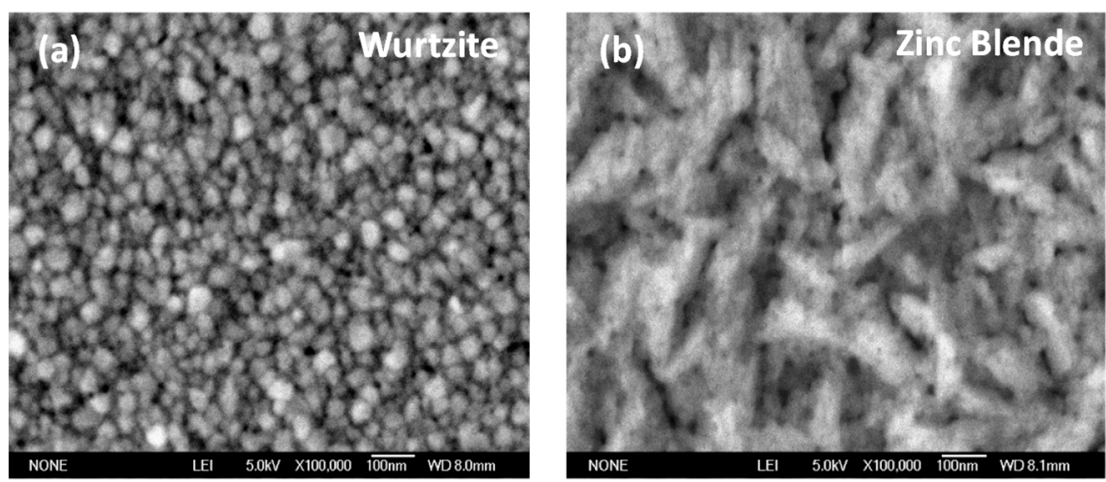

Figure 2. SEM images of the surfaces of the $\mathrm{ZnO}$ thin films. (a) Hexagonal phase. (b) Cubic phase.

Figure 2 shows SEM images of the wurtzite thin films on the left (a), and zinc blende thin films on the right (b). The scale is $1 \times 1 \mu \mathrm{m}$. Spheroid-like nanoparticle aggregates of $30 \mathrm{~nm}$ in diameter for the hexagonal wurtzite and nano-worms of $200 \mathrm{~nm}$ for the cubic zinc blende can be seen.

Photoluminescence (PL) measurements at RT were carried out on the $\mathrm{ZnO}$ thin films using an excitation wavelength of $310 \mathrm{~nm}(4.0 \mathrm{eV})$. Figure 3 shows the PL spectra of the hexagonal wurtzite $\mathrm{ZnO}$ thin films. It can be observed that the spectra include five bands at 2.30, 2.83, 3.34, 3.44 and $3.77 \mathrm{eV}$, respectively denoted as B1, B2, B3, B4 and B5. The principal band B2 $(2.83 \mathrm{eV})$ is the most intense in accordance with the literature reports [13-19] on hexagonal films. The B5 (3.77 eV) band at the ultraviolet range is attributed to some emission near the band gap edge, as reported in Fang et al. [13] and Tapa et al. [33]. The B5 (3.77 eV) band was also reported by Cui et al. [34] as an unusual ultraviolet emission for $\mathrm{ZnO}$ crystals. The $\mathrm{B} 1(2.35 \mathrm{eV})$ band at the visible spectrum is related to the exciton hole-electron pair at a deep level (DL) of the band gap of the $\mathrm{ZnO}$ caused by point defects, principally oxygen vacancies [33,35-38]. 


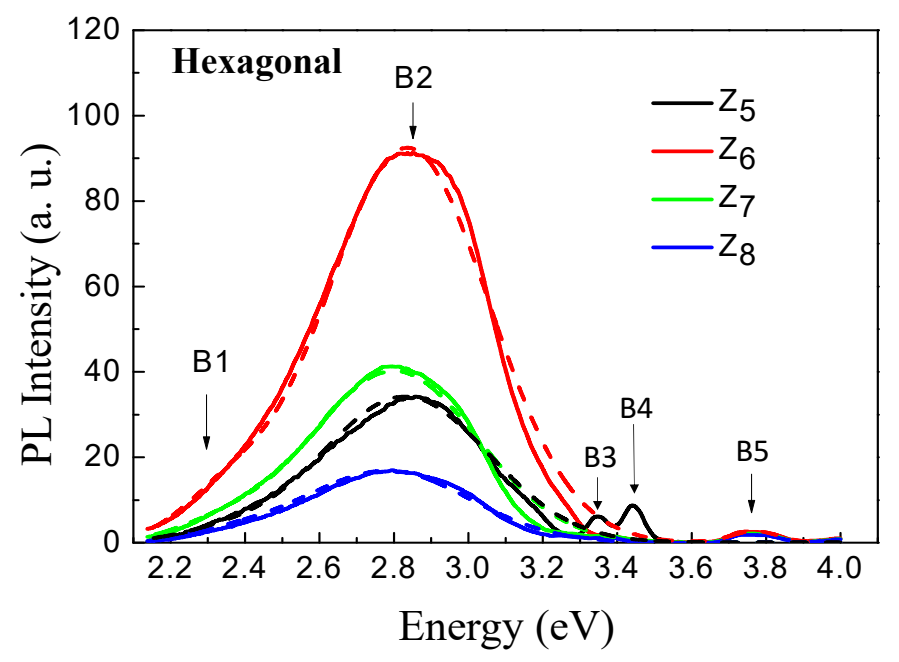

Figure 3. Photoluminescence spectra for the hexagonal wurtzite $\mathrm{ZnO}$ thin films. The dashed lines are the Gaussians, which were the references for the deconvolutions of the photoluminescence (PL) bands.

Figure $4 \mathrm{a}$, b shows the PL spectra for the cubic zinc blende $\mathrm{ZnO}$ thin films. It can be observed that the principal B2 $(2.83 \mathrm{eV})$ band appears in all samples. However, a new band also appears, denoted as $\mathrm{B} 6(2.70 \mathrm{eV})$. In these figures, the absence of the $\mathrm{B} 5(3.70 \mathrm{eV})$ band for the zinc blende films can be observed. Consequently, a shift to the red of the PL spectra of the zinc blende films with respect to the wurtzite films can be observed. Detailed deconvolution of the bands can be observed in Figure 5 . The B3 and B4 bands are related to the radiative recombination of donor-acceptor at the edge of the band gap, as predicted by Reynolds et al. [39]. In our previous work it was reported that the band gap of wurtzite $\mathrm{ZnO}(3.29 \pm 0.03 \mathrm{eV})$ has a similar value to that of the zinc blende phase $(3.18 \pm 0.03 \mathrm{eV})$ [12]. Consequently, by considering the near resemblance of the ion stacking in the lattice of both structures, the origin of the $\mathrm{B} 6$ band could be proposed to be generated by $\mathrm{Zn}$ interstitials [40,41]. The energy level of $\mathrm{Zn}$ vacancies $\left(\mathrm{V}_{\mathrm{Zn}}\right)$ in hexagonal $\mathrm{ZnO}$ is located at $0.50 \pm 0.02 \mathrm{eV}$, below the bottom of the conduction band (CB) [40], as illustrated in Figure 4c. It can be plausibly assumed the $\mathrm{V}_{\mathrm{zn}}$ level in the cubic phase is located at $0.50 \mathrm{eV}$, below the respective $\mathrm{CB}$ - taking into account that the exact value of the center of the emission band, in both cases, depends on the measured band gap value. In this manner, the $\mathrm{B} 2$ band $(2.83 \mathrm{eV})$ of the hexagonal phase is associated with the $\mathrm{V}_{\mathrm{Zn}}$ to valence band transition $[40,41]$ and, similarly, the B6 band of the cubic phase can be also identified with the $V_{z n}$ with a measurement of $2.68 \pm 0.02 \mathrm{eV}$ at the center of the band. 


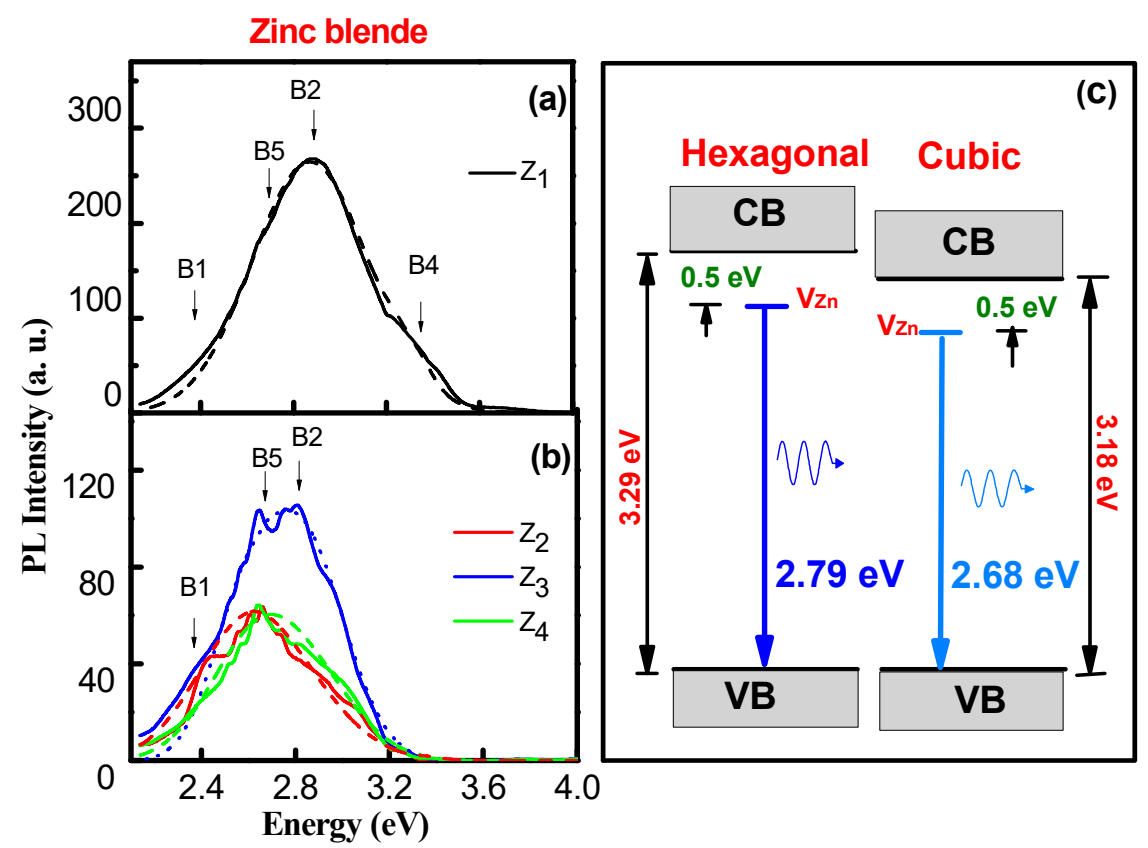

Figure 4. Photoluminescence spectra for the cubic zinc blende $\mathrm{ZnO}$ thin films. (a) The sample synthetized to $400{ }^{\circ} \mathrm{C}\left(Z_{1}\right)$. (b) Samples synthetized to $450{ }^{\circ} \mathrm{C}\left(Z_{2}\right), 500{ }^{\circ} \mathrm{C}\left(Z_{3}\right)$ and $550{ }^{\circ} \mathrm{C}\left(Z_{4}\right)$. The dashed lines are the Gaussians, which were the references for the deconvolutions of the PL bands. (c) $\mathrm{Zn}$ vacancy $\left(\mathrm{V}_{\mathrm{Zn}}\right)$ to valence-band $(\mathrm{VB})$ transitions in the hexagonal (left) and cubic (right) phases.

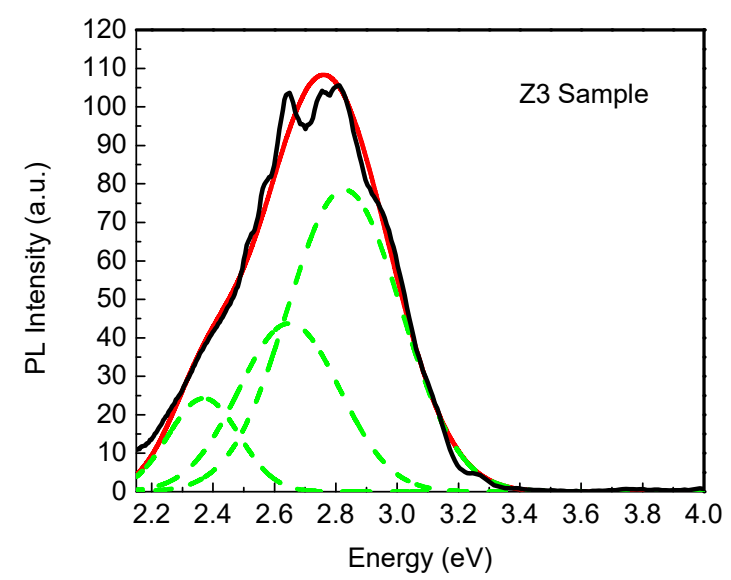

Figure 5. Deconvolution (green lines) of the PL spectrum of the cubic $Z_{3}$ sample showing the B6 band.

Figure 5 shows the explicit deconvolution of the cubic zinc blende $Z_{3}$ sample spectrum. The new $\mathrm{B} 6$ band at $2.70 \mathrm{eV}$ can clearly be observed. Also, in the same figure the high intensity of the photoluminescence of the B1 and B6 bands can be observed. It is important to mention that the high intensity of the $\mathrm{B} 1$ band should be attributed to the lack of oxygen in the cubic zinc blende $\mathrm{ZnO}$ thin films, as found in the EDS measurements.

Figure 6 shows the PL intensity of the Z7 (hexagonal) and Z3 (cubic) samples carried out at $77^{\circ} \mathrm{K}$ using an excitation wavelength of $325 \mathrm{~nm}$. Figure 6a shows two bands at 2.42 (B7) which correspond, respectively, to green emission and to 2.90 (B8) for the hexagonal phase. Moreover, with the aid of Lorentzian deconvolution, the new $\mathrm{B} 6$ band at $2.70 \mathrm{eV}$ for the cubic phase can again be clearly observed, as shown in Figure $6 \mathrm{~b}$, in addition to the B7 and B8 bands. It is important to mention that the emission of this $\mathrm{B} 6$ band corresponds to a blue emission. 


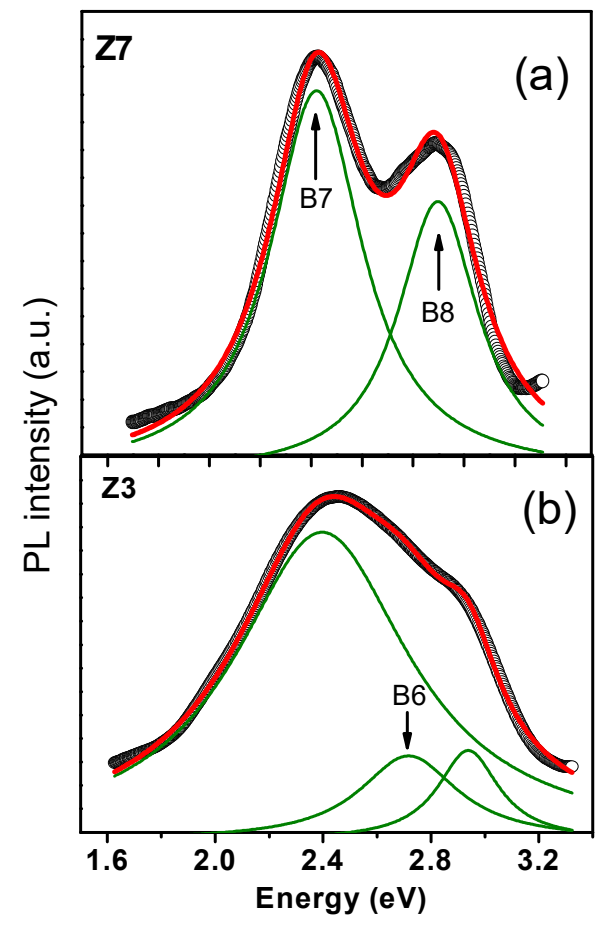

Figure 6. PL measurements at $77^{\circ} \mathrm{K}$ showing the B6 band for the cubic phase in the deconvolution of the spectra (green lines). (a) hexagonal films, (b) cubic films.

Vibrational properties of the samples were studied by means of Raman measurements. Figure 7 displays the $Z_{2}$ and $Z_{6}$ spectra of the samples, which correspond to $\mathrm{ZnO}$ in cubic and hexagonal symmetries, respectively. The spectra look quite similar, which is in accordance with Zahn et al. [42], who established that frequencies of the cubic modification vibrational modes nearly coincide with those of the hexagonal phase and generally cannot be used for the purpose of distinguishing the two structures. In the case of the $Z_{2}$ and $Z_{6}$ films, certain differences can be seen in the $350-600 \mathrm{~cm}^{-1}$ region. First principles calculations by Wang and co-workers [43] predicted for zinc blende ZnO Raman TO and LO modes at 365 and $516 \mathrm{~cm}^{-1}$. Figure 7 shows (black curve) modes at $340 \mathrm{~cm}^{-1}$ and $525 \mathrm{~cm}^{-1}$ which could be associated with the TO and LO modes reported in [43]. With regard to the wurtzite phase, the theory predicts the modes $\mathrm{A}_{1}{ }^{\mathrm{TO}}, \mathrm{E}_{1}{ }^{\mathrm{TO}}$ and $\mathrm{E}_{2}{ }^{\text {high }}$, at 350,371 and $401 \mathrm{~cm}^{-1}$, respectively. While $\mathrm{A}_{1}{ }^{\mathrm{TO}}$ and $\mathrm{E}_{2}{ }^{\text {high }}$ were not observed in this work, $\mathrm{E}_{1}{ }^{\mathrm{TO}}$ was at $414 \mathrm{~cm}^{-1}$, in agreement with the experimental results: $409 \mathrm{~cm}^{-1}$ [43] and $420 \mathrm{~cm}^{-1}$ [44]. This mode could be resolved by deconvolution, as shown in the inset of Figure 7a. Since the excitation beam is normal to the surface of the film, i.e., perpendicular to planes (002) and (004) of the hexagonal and cubic phases, respectively (observe inset of Figure 1), the electric field of the light is parallel to these planes. So, the excitation of the mode $\mathrm{E}_{1}^{\mathrm{TO}}$ (see inset of Figure $7 \mathrm{~b}$ ) is more favored in the hexagonal phase than in the cubic. Other modes observed in the hexagonal phase are $\mathrm{B}_{1}{ }^{\text {high }}: 510 \mathrm{~cm}^{-1}, \mathrm{~A}_{1}{ }^{\mathrm{LO}}: 501 \mathrm{~cm}^{-1}$ and $\mathrm{E}_{1}{ }^{\mathrm{LO}}: 508 \mathrm{~cm}^{-1}[43,45]$. These three phonons could all be present to shape the band centered at $505 \mathrm{~cm}^{-1}$ of Figure 7, which is denoted as $\mathrm{A}_{1}{ }^{\mathrm{LO}}$. The modes at around 650 and $800 \mathrm{~cm}^{-1}$ have been identified in hexagonal $\mathrm{ZnO}$ with multi-phonons [46] and surface phonons [47], respectively. In this way, our ZnO Raman results are reasonably supported for theoretical calculations and experimental reports. 


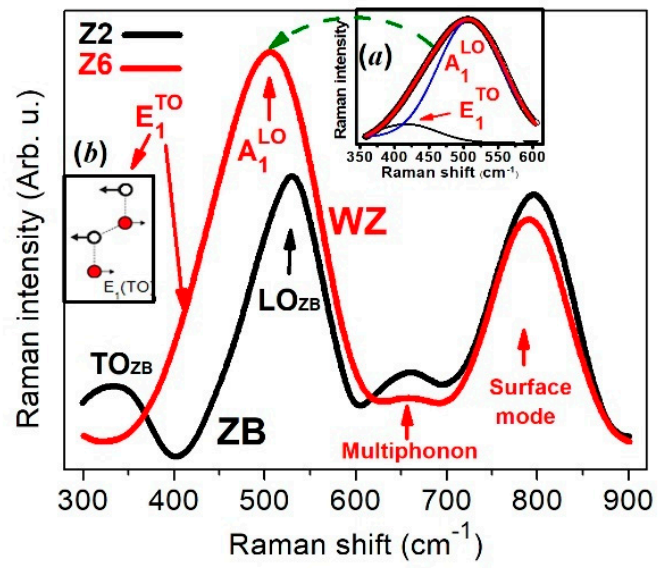

Figure 7. Raman spectroscopy measurements at room temperature (RT) carried out on $Z_{2}$ (zinc blende) and $Z_{6}$ (wurtzite) samples. Inset (a) exhibits a deconvolution of the band of the WZ phase in the $350-600 \mathrm{~cm}^{-1}$ interval. $\mathrm{E}_{2}{ }^{\mathrm{H}}$ means $\mathrm{E}_{2}{ }^{\text {high }}$. Inset (b) shows the vibration of ions in the $\mathrm{E}_{2}{ }^{\text {high }}$ mode.

\section{Conclusions}

Cubic zinc blende $\mathrm{ZnO}$ thin films were grown on glass substrates by means of the spray pyrolysis technique. Raman measurements supported the growth of $\mathrm{ZnO}$ in the cubic phase. The structural characterization showed spheroid-like nanoparticles with $30 \mathrm{~nm}$ diameters for hexagonal wurtzite and nano-worm-like structures of $200 \mathrm{~nm}$ for cubic zinc blende films. In relation to the optical characterization, the unfolding of the principal band of the photoluminescence spectra of cubic zinc blende $\mathrm{ZnO}$ thin films was shown. A photoluminescence band peaked at $2.70 \mathrm{eV}$, characteristic for cubic rock-salt $\mathrm{ZnO}$. This was ascribed to the exciton recombination of the hole-electron pair of the forbidden band gap that presented in the fabricated zinc blende $\mathrm{ZnO}$ thin films. It is important to emphasize that this band corresponds to a blue emission, which opens the applicability of these films as light-emitting devices. Additionally, EDS and PL studies suggest oxygen vacancies to be present in the cubic zinc blende $\mathrm{ZnO}$ thin films, which promote the green emission shown by the $\mathrm{B} 7$ band in the PL measurements at $77^{\circ} \mathrm{K}$. It is important to mention that some PL bands of cubic films are also observed for the hexagonal phase due to the similar ion stacking in both wurtzite and zincblende symmetries, which commonly gives place to polytypism in these $\mathrm{ZnO}$ thin films, as was reviewed by Ashrafi and Jagadish [9].

Author Contributions: Conceptualization, N.M.-A. and O.Z.-A.; methodology, L.M.-P. and E.V.H.; validation, O.Z.-A.; investigation, N.M.-A., O.Z.-A. and L.M.-P.; writing-original draft preparation, N.M.-A. and O.Z.-A.; writing-review and editing, L.F.-H. and S.M.A.; supervision, O.Z.-A.; funding acquisition, N.M.-A. and L.F.-H.

Funding: This research received no external funding.

Acknowledgments: This work was partially supported by the Instituto Politécnico Nacional, México, with the project number SIP20195580. The authors would also like to acknowledge the technical assistance of Ing. Ana Berta Soto and Dr. Angel Guillen for obtaining the SEM images, as well as QFB Marcela Guerrero, all from the Physics Department of CINVESTAV-IPN, México. The authors want to acknowledge Dra. Patricia Rodriguez Fragoso from the Physics Department of CINVESTAV-IPN, México, for measuring the PL spectra at $77^{\circ} \mathrm{K}$. The authors also want to acknowledge Margarita Mondragón Chaparro from the Sección de Estudios de Posgrado e Investigación de la ESIME Unidad Azcapotzalco, México.

Conflicts of Interest: The authors declare no conflict of interest.

\section{References}

1. Choi, K.S.; Chang, S.P. Effect of structure morphologies on hydrogen gas sensing by ZnO Nanotubes. Mater. Lett. 2018, 230, 48-52. [CrossRef]

2. Sonker, R.K.; Sikarwar, S.; Sabhajeet, S.R.; Yadav, B.C. Spherical growth of nanostructures ZnO based optical sensing and photovoltaic application. Opt. Mater. 2018, 83, 342-347. [CrossRef] 
3. Patil, V.L.; Vanalakar, S.A.; Patil, P.S.; Kim, J.H. Fabrication of nanostructured ZnO thin films based $\mathrm{NO}_{2}$ gas sensor via SILAR technnique. Sens. Actuators B 2017, 239, 1185-1193. [CrossRef]

4. Hunge, Y.M.; Yadav, A.A.; Kulkarni, S.B.; Mathe, V.L. A multifunctional ZnO thin film based devices for photoelectrocatalytic degradation of terephthalic acid and $\mathrm{CO}_{2}$ gas sensing applications. Sens. Actuators $B$ 2018, 274, 1-9. [CrossRef]

5. Gao, X.; Zhang, T. An overview: Facet-dependent metal oxide semiconductor gas sensors. Sens. Actuators $B$ 2018, 277, 604-633. [CrossRef]

6. Fairose, S.; Ernest, S.; Daniel, S. Effect of Oxygen Sputter Pressure on the Structural, Morphological and Optical Properties of ZnO Thin Films for Gas Sensing Application. Sens. Imaging 2018, 19, 1. [CrossRef]

7. Martínez Pérez, L.; Aguilar, M.; Zelaya-Angel, O.; Muñoz-Aguirre, N. Improved electrical, optical, and structural properties of undoped $\mathrm{ZnO}$ thin films grown by water-mist-assisted spray pyrolysis. Phys. Stat. Solidi A 2006, 203, 2411-2417. [CrossRef]

8. Ö̈zür, Ü.; Alivov, Y.I.; Liu, C.; Teke, A.; Reshchikov, M.A.; Dogan, S.; Aurutin, V.; Cho, S.-J.; Morkoc, H. A comprehensive review of $\mathrm{ZnO}$ materials and devices. J. Appl. Phys. 2005, 98, 041301. [CrossRef]

9. Ashrafi, A.; Jagadish, C. Review of zincblende ZnO: Stability of metastable ZnO phases. J. Appl. Phys. 2007, 102, 071101. [CrossRef]

10. Rosales-Córdova, A.; Castañeda-Guzmán, R.; Sanchez-Aké, C. Zinc blende phase detection in ZnO thin films grown with low doping Mn concentration by double-beam pulsed laser deposition. J. Mater. Sci. Mater. Electron. 2018, 29, 18971-18977. [CrossRef]

11. Wang, X.D.; Zhou, H.; Wang, H.Q.; Ren, F.; Chen, X.H.; Zhan, H.H.; Zhou, Y.H.; Kang, J.Y. Cubic ZnO films obtained at low pressure by molecular beam epitaxy. Chin. Phys. B 2015, 24, 097106. [CrossRef]

12. Martínez-Pérez, L.; Muñoz-Aguirre, N.; Muñoz-Aguirre, S.; Zelaya-Angel, O. Nanometric structures of highly oriented zinc blende $\mathrm{ZnO}$ thin films. Mater. Lett. 2015, 139, 63-65. [CrossRef]

13. Fang, Z.; Wang, Y.; Xu, D.; Tan, Y.; Liu, X. Blue Luminescent Center in ZnO Film Deposited on Silicon Substrates. Opt. Mater. 2004, 26, 239-242. [CrossRef]

14. Xu, X.; Xu, C.; Dai, J.; Pan, J.; Hu, J. Evolutions of defects and blue-green emissions in ZnO microwhiskers fabricated by vapor-phase transport. J. Phys. Chem. Solids 2012, 73, 858-862. [CrossRef]

15. Zeng, H.; Duan, G.; Li, Y.; Yang, S.; Xu, X.; Cai, W. Blue Luminescence of ZnO Nanoparticles Based on Non-Equilibrium Processes: Defect Origins and Emission Controls. Adv. Funct. Mater. 2010, 20, 561-572. [CrossRef]

16. Micro Concentrated Cleaning Solution, International Products, Burlington, N.J. Available online: https: //www.ipcol.com/cleaners/micro-90 (accessed on 25 January 2018).

17. Kolodziejczak-Radzimska, A.; Jesionowski, T. Zinc Oxide-From Synthesis to Application: A Review. Materials 2014, 7, 2833-2881. [CrossRef] [PubMed]

18. Shiojiri, M.; Kaito, C. Structure and growth of $\mathrm{ZnO}$ smoke particles prepared by gas evaporation technique. J. Cryst. Growth 1981, 52, 173-177. [CrossRef]

19. Morkoç, H.; Özgür, Ü. Zinc Oxide: Fundamentals, Materials and Device Technology; Wiley VCH Verlag GmbH\&Co. KGaA: Weinheim, Germany, 2005.

20. Rahman, F. Zinc oxide light-emitting diodes: A review. Opt. Eng. 2019, 58, 1. [CrossRef]

21. Willander, M.; Nur, O.; Zhao, Q.X.; Yang, L.L.; Lorenz, M.; Cao, B.Q.; Zuñiga-Perez, J.; Czekalla, C.; Zimmermann, G.; Grundmann, M.; et al. Zinc oxide nanorod based photonic devices: Recent progress in growth, light emitting diodes and lasers. Nanotechnology 2009, 20, 332001. [CrossRef] [PubMed]

22. Son, D.I.; Kwon, B.W.; Park, D.H.; Seo, W.-S.; Yi, Y.; Angadi, B.; Lee, C.-L.; Choi, W.K. Emissive ZnO-graphene quantum dots for white-light-emitting diodes. Nat. Nanotechnol. 2012, 7, 465-471. [CrossRef] [PubMed]

23. Jin, B.J.; Im, S.; Lee, S.Y. Violet and UV luminescence emitted from ZnO thin films grown on sapphire by pulsed laser deposition. Thin Solid Films 2000, 366, 107-110. [CrossRef]

24. Sanchez-Valencia, J.R.; Alcaire, M.; Romero-Gómez, P.; Macias-Montero, M.; Aparicio, F.J.; Borras, A.; Gonzalez-Elipe, A.R.; Barranco, A. Oxygen Optical Sensing in Gas and Liquids with Nanostructured ZnO Thin Films Based on Exciton Emission Detection. J. Phys. Chem. C 2014, 118, 9852-9859. [CrossRef]

25. Tumbul, A.; Aslan, F.; Demirozu, S.; Goktas, A.; Kilic, A.; Durgun, M.; Zarbali1, M.Z. Solution processed boron doped $\mathrm{ZnO}$ thin films: Influence of different boron complexes. Mater. Res. Express 2019, 6, 035903. [CrossRef] 
26. El Sayed, A.M.; Taha, S.; Said, G.; Al-Ghamdi, A.A.; Yakuphanoglu, F. Structural and optical properties of spin coated $\mathrm{Zn}_{1-x} \mathrm{Cr}_{x} \mathrm{O}$ nanostructures. Superlattices Microstruct. 2013, 60, 108-119. [CrossRef]

27. Wang, T.; Wu, H.; Wang, Z.; Chen, C.; Liu, C. Blue light emission from the heterostructured ZnO/InGaN/GaN. Nanoscale Res. Lett. 2013, 8, 99. [CrossRef] [PubMed]

28. Alamé, S.; Navarro Quezada, A.; Skuridina, D.; Reich, C.; Henning, D.; Frentrup, M.; Wernicke, T.; Koslow, I.; Kneissl, M.; Esser, N.; et al. Preparation and structure of ultra-thin $\mathrm{Ga}(0001)$ layers on $\operatorname{In}_{0.11} \mathrm{Ga}_{0.89} \mathrm{~N}$-single quantum Wells. Mater. Sci. Semicond. Proc. 2016, 55, 7-11. [CrossRef]

29. Ahmed, A.; Ali, T.; Siddique, M.N.; Ahmad, A.; Tripathi, P. Enhanced room temperature ferromagnetism in $\mathrm{Ni}$ doped $\mathrm{SnO}_{2}$ nanoparticles: A comprehensive study. J. Appl. Phys. 2017, 122, 083906. [CrossRef]

30. Ahmad, N.; Khan, S. Effect of (Mn-Co) co-doping on the structural, morphological, optical, photoluminescence and electrical properties of $\mathrm{SnO}_{2}$. J. Alloys Compd. 2017, 720, 502-509. [CrossRef]

31. Guo, L.; Yang, S.; Yang, C.; Yu, P.; Wang, J.; Ge, W.; Wong, G.K.L. Highly monodisperse polymer-capped ZnO nanoparticles: Preparation and optical properties. Appl. Phys. Lett. 2000, 76, 2901-2903. [CrossRef]

32. $\mathrm{Hu}, \mathrm{Y}$.; Chen, H.-J. Origin of green luminescence of $\mathrm{ZnO}$ powders reacted with carbon black. J. Appl. Phys. 2007, 101, 124902. [CrossRef]

33. Thapa, D.; Huso, J.; Morrison, J.L.; Corolewski, C.D.; McCluskey, M.D.; Bergman, L. Achieving highly-enhanced UV photoluminescence and its origin in $\mathrm{ZnO}$ nanocrystalline films. Opt. Mater. 2016, 58, 382-389. [CrossRef]

34. Cui, M.; Jin, H.; Xi, L.; Wang, Y.; Townsend, P.D. Photoluminescence identification of surface contaminants on zinc oxide from their phase transitions. Spectrosc. Lett. 2018, 51, 274-278. [CrossRef]

35. Davood, R. Synthesis and photoluminescence characterization of ZnO nanoparticles. J. Lumin. 2013, 134, 213-219. [CrossRef]

36. Uthirakumar, P.; Hong, C.H. Effect of annealing temperature and $\mathrm{pH}$ on morphology and optical property of highly dispersible ZnO nanoparticles. Mater. Charact. 2009, 60, 1305-1310. [CrossRef]

37. Repp, S.; Erdem, E. Controlling the exciton energy of zinc oxide $(\mathrm{ZnO})$ quantum dots by changing the confinement conditions. Spectrochim. Acta Part A Mol. Biomol. Spectrosc. 2016, 152, 637-644. [CrossRef] [PubMed]

38. Repp, S.; Weber, S.; Erdem, E. Defect Evolution of Nonstoichiometric ZnO Quantum Dots. J. Phys. Chem. C 2016, 120, 25124-25130. [CrossRef]

39. Reynolds, D.C.; Look, D.C.; Jogai, B.; Litton, C.W.; Collins, T.C.; Harsch, W.; Cantwell, G. Neutral-donor-bound-exciton complexes in ZnO crystals. Phys. Rev. B 1998, 57, 12151. [CrossRef]

40. Willander, M.; Nur, O.; Rana Sadaf, J.; Israr Qadir, M.; Zaman, S.; Zainelabdin, A.; Bano, N.; Ijaz, H. Luminescence from Zinc Oxide Nanostructures and Polymersand their Hybrid Devices. Materials 2010, 3 , 2643-2667. [CrossRef]

41. Kayaci, F.; Vempati, S.; Donmez, I.; Biyikliab, N.; Uyar, T. Role of zinc interstitials and oxygen vacancies of ZnO in photocatalysis: A bottom-up approach to control defect density. Nanoscale 2014, 6, 10224-10234. [CrossRef]

42. Zahn, D.R.T.; Maierhofer, C.; Winter, A.; Reckzügel, M.; Srama, R.; Rossow, U.; Thomas, A.; Horn, K.; Richter, W. In situ monitoring of heterostructure growth by optical spectroscopies: CdS on InP (110). Appl. Surf. Sci. 1992, 56-58, 684-690. [CrossRef]

43. Wang, Z.; Wang, F.; Wang, L.; Jia, Y.; Sun, Q. First-principles study of negative thermal expansion in zinc oxide. J. Appl. Phys. 2013, 114, 063508. [CrossRef]

44. Sokolov, P.S.; Baranov, A.N.; Dobrokhotov, Z.V.; Solozhenko, V.L. Solozhenko, Synthesis and Thermal Stability of Cubic ZnO in the Salt Nanocomposites. Russ. Chem. Bulletin 2010, 19, 325. [CrossRef]

45. Cerqueira, M.F.; Vasilevskiy, M.I.; Oliveira, F.; Rolo, A.G.; Viseu, T.; Ayres de Campos, J.; Alves, E.; Correia, R. Resonant Raman scattering in $\mathrm{ZnO}: \mathrm{Mn}$ and $\mathrm{ZnO}: \mathrm{Mn}: \mathrm{Al}$ thin films grown by RF sputtering. J. Phys. Condens. Matter 2011, 23, 334205. [CrossRef] [PubMed]

46. Vinogradov, E.A.; Mel'nikA, N.N.; TsurkanL, E.; Kicherman, V. Raman spectra of ZnO single cristal. J. Appl. Spectrosc. 1977, 26, 764-767. [CrossRef]

47. Nikitenko, V.A.; Plekhanov, V.G.; Mukhin, S.V. Raman spectra of oxide zinc powders and single crystals. J. Appl. Spectrosc. 1996, 63, 290-292. [CrossRef]

(C) 2019 by the authors. Licensee MDPI, Basel, Switzerland. This article is an open access article distributed under the terms and conditions of the Creative Commons Attribution (CC BY) license (http://creativecommons.org/licenses/by/4.0/). 